\title{
Theoretical study on the electronic, structural, properties and reactivity of a series of mono-, di-, tri- and tetrachlorothiophenes as well as corresponding radical cation forms as monomers for conducting polymers
}

\author{
Hossein Shirani IL Beigi ${ }^{{ }^{*}}$, Saeed Jameh-Bozorghi
}

\begin{abstract}
In this paper, electrical and structural properties of mono-, di-, tri- and tetrachlorothiophenes and their radical cations have been studied using the density functional theory and B3LYP method with $6-311++G^{* *}$ basis set. The effects of the number and position of the substituent of chlorine atoms on the properties of the thiophene ring for all chlorothiophenes and their radical cations have been studied. Vibrational frequencies, nuclear chemical shielding constants, spin-density distribution, size and direction of dipole moment vector, ionization potential, electric polarizabilities and NICS values of these compounds have been calculated as well. The analysis of these data showed that double bonds in 3-chlorothiophene are more delocalized and it is the best possible candidate monomer among all chlorothiophenes for the synthesis of corresponding conducting polymers with modified characteristics.
\end{abstract}

\section{Introduction}

Electrically-conducting polymers such as advanced materials and the new class of 'synthetic metals' have drawn high attention in the last years [1]. The 2000 Nobel Prize in chemistry recognized the discovery of conducting polymers and over 25 years of progress in this field $[2,3]$. There has been growing interest in research on conducting polymer nano structures (nanorods, -tubes, -wires and-fibers) since they incorporate the advantages of organic conductors with low-dimensional systems and so create interesting physicochemical properties and potentially useful applications [4-7]. The varieties of such studies have been reported in the literature that includes: surfactants [8-11], liquid crystals [12], polyelectrolytes [13], nano-wire seeds [14], thiophene oligomers [15], bulky organic dopants [16-21]. Among intrinsic conducting polymers with conjugated double

\footnotetext{
* Correspondence: shiranihossein@gmail.com

'Young Researchers Club, Islamic Azad University, Toyserkan Branch, Toyserkan, Iran

Full list of author information is available at the end of the article
}

bonds, polythiophenes (PTHs) and related derivatives are suitable for commercial applications [22].

Polythiophenes are normally produced from non aqueous media because the monomer is more soluble in them. The influence of water on polymerization process of thiophene as well as on the redox switching properties has been studied $[23,24]$. It has been recently shown that the attachment of a range of electron-donating or electron-withdrawing groups through a conjugated linker has a dramatic effect on polymerization potential and subsequent photovoltaic performance $[25,26]$. Polythiophene has a solubility of $75 \%(\mathrm{w} / \mathrm{w})$ in chloroform and a conductivity of $220 \mathrm{~s} \mathrm{~cm}^{-1}$ [22].

The effect of temperature on polymerization process of thiophene has been investigated as well [27]. Results show that when polymerization is carried out at 15$20^{\circ} \mathrm{C}$, polymers with optimal properties will be obtained. Ultrasonication has been used to improve the efficiency (improved yield, lowering of polymerization potentials) of electropolymerization process of polythiophene [28]. 
Thiophene is oxidized to form a conducting electro active polymer (CEP), with the best conductivity when it is created from $\alpha-\alpha$ linkages [22]. In polypyrroles, the mechanism of polymerization involves the formation of radical cations which react with another monomer to develop the polymeric structure (Figure 1) [29].

The objective of the present research is to study electronic and structural properties of all chlorothiophenes (shown in Figure 2) and their radical cations using DFT-B3LYP and DFT-UB3LYP methods.

The electropolymerization and characteristics of monomers (conductivity and solubility) are related to the stability of their radical cations which it is closely dependent on the type and configuration of the substituent on the thiophene ring [22]. Vibrational frequencies with analyses of their IR intensities and NMR shielding constants will be used to characterize and predict the molecular and spectroscopic properties of fluorothiophenes.

\section{Computational Procedures}

First of all, structures of representative mono-, di-, triand tetrachlorothiophenes were optimized using B3LYP/ $6-311++G^{* * *}$ method [30-32]. The geometries of these compounds were optimized using standard gradient techniques with default parameters set in G98W. Vibrational frequencies with their IR intensities are calculated with scale factors, $f_{=} 1.0100$ for low-frequency vibrations (below $1000 \mathrm{~cm}^{-1}$ ) and $f_{=} 0.9679$ for high-frequency vibrations (above $1000 \mathrm{~cm}^{-1}$ ) [33]. The vibrational

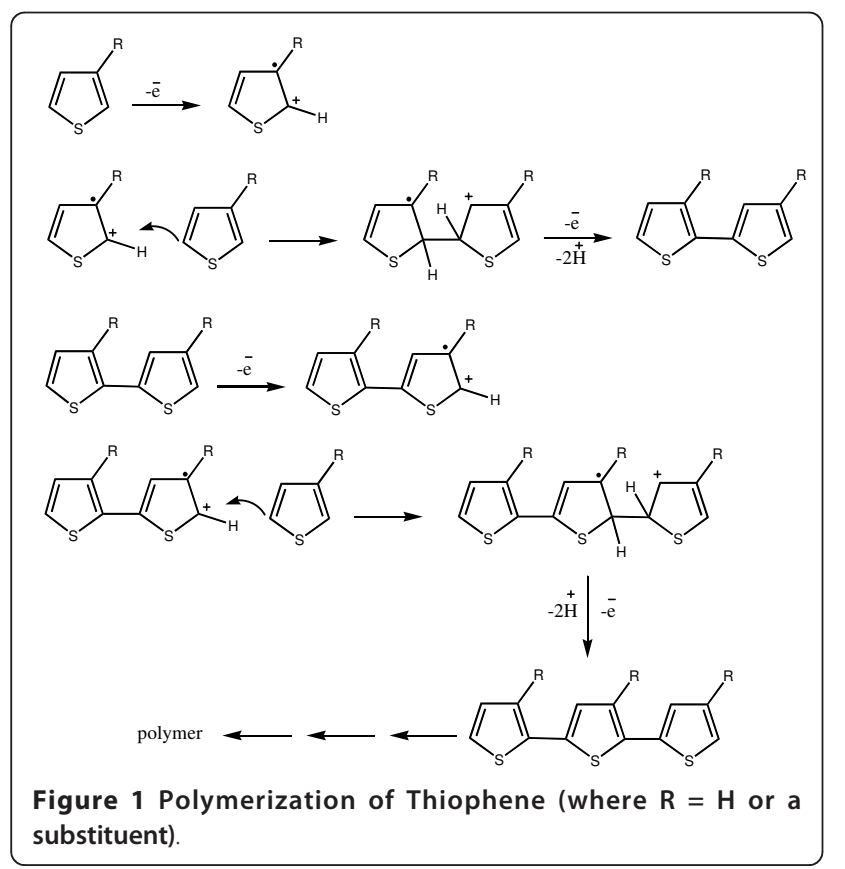

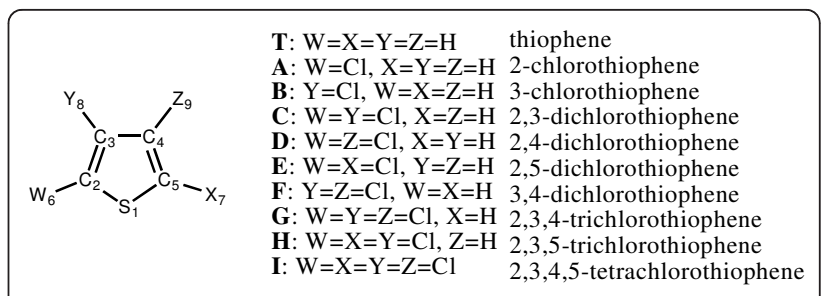

Figure 2 All possible mono-, di-, tri- and tetrachlorothiophenes studied in this work.

frequencies analysis showed that all structures correspond to local minima in potential energy surface.

\section{Results and Discussion}

\section{Structural Analysis of Chlorothiophenes}

In this section, the electrical and structural properties of chlorothiophenes and their related radical cations have been studied. Because of the stabilizing effects of the delocalization of non-bonding $p$ electrons of sulfur atom, it is expected that the thiophene molecules possess a plane structure.

In agreement with this expectation, results of the present calculations show that all chlorothiophenes possess planar structures (the optimized values of all dihedral angles of all structures are either $0^{\circ}$ or $180^{\circ}$ ). The optimized structural parameters obtained at B3LYP/6-311+ $+G^{* * *}$ level of theory for all chlorothiophenes and UB3LYP/6-311++G* level of theory for all radical cations are listed in Tables 1 and 2 .

To predict the bonding-characteristic behavior of chlorothiophene rings in their corresponding polymer chains and to determine the extent of the $\pi$-conjugation character of these polymers, we have used the $\boldsymbol{F}_{\boldsymbol{n}}$ coefficient defined in Equation 1 for each thiophene ring [34].

$$
F_{n}=\frac{\mathrm{R} 34}{(\mathrm{R} 23+\mathrm{R} 45) / 2}
$$

where R34 is the length of $\mathrm{C}_{3}-\mathrm{C}_{4}$ bond (formally single bond) and [(R23 + R45)/2] is the average length of $\mathrm{C}_{2}-\mathrm{C}_{3}$ and $\mathrm{C}_{4}-\mathrm{C}_{5}$ bonds (formally double bonds) in the thiophene ring. The calculated values of the $\boldsymbol{F}_{\boldsymbol{n}}$ coefficient for thiophene, all chlorothiophenes and their radical cations are listed in Table 1. As shown in this table, $\boldsymbol{F}_{\boldsymbol{n}}$ coefficient has the following trend for all molecules:

$$
\text { B }<\text { Thiophene }<\mathrm{C}<\mathrm{A}<\mathrm{D}<\mathrm{H}<\mathrm{E}<\mathrm{F}<\mathrm{G}<\text { I }
$$

And for all molecular radical cations, values of the $\boldsymbol{F}_{\boldsymbol{n}}$ coefficient has the following trend:

$$
\text { B }<\text { Thiophene }<\mathrm{A}<\mathrm{E}<\mathrm{G}=\mathrm{H}<\mathrm{F}=\mathrm{I}<\mathrm{D}<\mathrm{C}
$$

As this table shows, 3-chlorothiophene has the smallest value of the $\boldsymbol{F}_{\boldsymbol{n}}$ coefficient. Therefore, it can be 
Table 1 B3LYP/6-311++G** optimized values of bond lengths $(\AA)$ and the $F_{n}$ coefficient for Thiophene and Chlorothiophenes

\begin{tabular}{ccccccc}
\hline Molecule & S1-C2 & S1-C5 & C2-C3 & C3-C4 & C4-C5 & Fn \\
\hline Thiophene & 1.733 & 1.733 & 1.366 & 1.428 & 1.366 & 1.045 \\
& 1.728 & 1.728 & 1.422 & 1.376 & 1.421 & 0.968 \\
\hline A & 1.740 & 1.737 & 1.364 & 1.428 & 1.364 & 1.047 \\
& 1.760 & 1.715 & 1.419 & 1.378 & 1.414 & 0.973 \\
\hline B & 1.732 & 1.733 & 1.363 & 1.424 & 1.364 & $\mathbf{1 . 0 4 4}$ \\
& 1.681 & 1.780 & 1.437 & 1.341 & 1.366 & $\mathbf{0 . 9 5 7}$ \\
\hline C & 1.741 & 1.735 & 1.367 & 1.427 & 1.362 & 1.046 \\
& 1.732 & 1.743 & 1.445 & 1.395 & 1.383 & 0.987 \\
\hline D & 1.740 & 1.737 & 1.362 & 1.427 & 1.361 & 1.048 \\
& 1.782 & 1.700 & 1.385 & 1.386 & 1.431 & 0.984 \\
\hline E & 1.745 & 1.745 & 1.362 & 1.429 & 1.361 & 1.050 \\
& 1.750 & 1.750 & 1.410 & 1.379 & 1.410 & 0.978 \\
\hline F & 1.730 & 1.730 & 1.363 & 1.433 & 1.363 & 1.051 \\
& 1.733 & 1.734 & 1.413 & 1.387 & 1.412 & 0.982 \\
\hline G & 1.738 & 1.734 & 1.367 & 1.435 & 1.360 & 1.052 \\
& 1.754 & 1.728 & 1.415 & 1.386 & 1.411 & 0.981 \\
\hline H & 1.747 & 1.744 & 1.365 & 1.429 & 1.360 & 1.049 \\
& 1.734 & 1.768 & 1.430 & 1.383 & 1.390 & 0.981 \\
\hline I & 1.745 & 1.743 & 1.364 & 1.437 & 1.364 & 1.053 \\
& 1.752 & 1.752 & 1.413 & 1.388 & 1.413 & 0.982 \\
\hline & 1 & & & & & \\
& & &
\end{tabular}

Corresponding values for the related radical cations optimized with UB3LYP/6$311++G^{* *}$ are given in the lower row with italic fonts. See Figure 2 for definitions of bond lengths. suggested that double bonds in 3-chlorothiophene are more delocalized.

\section{Spin-Distribution Analysis}

Electropolymerization process for each molecular radical cation is obtained from $\alpha-\alpha\left(\mathbf{C}_{2}-\mathbf{C}_{5}\right)$ linkages [29], so it can be said that in a compound, the greater spin density in Positions $\mathbf{C}_{3}$ and $\mathbf{C}_{\mathbf{4}}$ is, the higher electropolymerization rate will be [35].

The spin-density distribution over the ring atoms of chlorothiophene radical cations have been calculated and presented in Table 3. As shown in this table, it is obvious that monomers $\mathbf{B}$ and $\mathbf{F}$ have the maximal spin density on positions $\mathbf{C}_{\mathbf{3}}$ and $\mathbf{C}_{\mathbf{4}}$. This means that the electropolymerization of 3-chlorothiophene (B) and 3,4dichlorothiophene $(\mathbf{F})$ can be more favorable ratio with respect to other molecules.

\section{Electric Dipole Moments}

Orientations of the polymer chains in the condensed phase are the most important parameters affecting the electric charge transport properties of polymers so that the electrical conductivity of a polymer chain is altered when its orientation and consequently its symmetry and non isotropic interactions are changed.

Chemically synthesized PTHs powders exhibit a partially crystalline structure in which the chains align and

Table 2 B3LYP/6-311++G** optimized values of bond angles for Thiophene and Chlorothiophenes

\begin{tabular}{ccccccccc}
\hline Molecule & C2-S1-C5 & S1-C2-W & S1-C5-X & S1-C2-C3 & S1-C5-C4 & C3-C4-C5 & C2-C3-Y & C5-C4-Z \\
\hline Thiophene & 91.5 & 119.9 & 119.9 & 111.5 & 111.5 & 112.7 & 123.4 & 123.4 \\
& 89.7 & 120.1 & 120.1 & 113.3 & 113.3 & 111.9 & 122.6 & 122.6 \\
\hline A & 90.7 & 120.5 & 119.6 & 112.5 & 111.8 & 111.8 & 123.4 & 123.3 \\
& 88.0 & 120.0 & 119.4 & 114.9 & 114.2 & 112.8 & 122.7 & 122.3 \\
\hline B & 91.7 & 121.1 & 119.9 & 110.6 & 111.9 & 111.6 & 123.4 & 124.6 \\
& 90.6 & 123.1 & 118.8 & 111.4 & 113.4 & 110.0 & 120.7 & 125.2 \\
\hline C & 91.0 & 120.9 & 120.8 & 119.6 & 112.2 & 112.3 & 124.2 & 124.5 \\
& 88.2 & 122.9 & 118.2 & 113.4 & 115.4 & 110.7 & 120.6 & 124.5 \\
\hline D & 90.9 & 120.4 & 120.4 & 112.8 & 110.8 & 114.6 & 124.5 & 123.4 \\
& 88.5 & 118.4 & 121.9 & 115.5 & 112.4 & 115.1 & 125.0 & 120.4 \\
\hline E & 89.9 & 120.1 & 120.0 & 112.7 & 112.7 & 112.4 & 123.4 & 123.4 \\
& 86.3 & 119.4 & 119.4 & 115.8 & 115.8 & 111.1 & 122.5 & 122.5 \\
\hline F & 91.9 & 120.9 & 120.9 & 111.3 & 111.3 & 112.8 & 123.6 & 123.6 \\
& 89.9 & 122.9 & 121.5 & 113.0 & 112.9 & 112.1 & 123.1 \\
\hline G & 91.3 & 120.6 & 120.5 & 112.1 & 111.5 & 113.4 & 124.4 & 123.2 \\
\hline H & 88.3 & 121.2 & 120.7 & 114.5 & 114.1 & 112.9 & 123.2 & 122.8 \\
\hline & 90.3 & 120.1 & 120.4 & 113.0 & 111.6 & 113.5 & 124.5 & 124.2 \\
& 86.7 & 121.8 & 118.0 & 114.1 & 116.8 & 109.4 & 120.9 & 124.5 \\
\hline
\end{tabular}


Table 3 Distribution of spin density over sulfur and carbon atoms in UB3LYP/6-311++G** optimized structures of Thiophene and Chlorothiophenes radical cations

\begin{tabular}{cccccc}
\hline Molecule & $\mathbf{S}_{\mathbf{1}}$ & $\mathbf{C}_{\mathbf{2}}$ & $\mathbf{C}_{\mathbf{3}}$ & $\mathbf{C}_{\mathbf{4}}$ & $\mathbf{C}_{\mathbf{5}}$ \\
\hline Thiophene & -0.131 & 0.547 & 0.046 & 0.046 & 0.548 \\
A & -0.087 & 0.377 & 0.055 & 0.049 & 0.456 \\
B & 0.041 & 0.356 & $\mathbf{0 . 2 8 9}$ & -0.179 & 0.357 \\
C & -0.081 & 0.358 & 0.186 & -0.108 & 0.399 \\
D & 0.003 & 0.315 & -0.124 & 0.162 & 0.425 \\
E & -0.088 & 0.343 & 0.061 & 0.061 & 0.343 \\
F & 0.419 & -0.110 & $\mathbf{0 . 2 3 6}$ & 0.240 & -0.109 \\
G & -0.065 & 0.384 & -0.044 & 0.014 & 0.470 \\
H & -0.062 & 0.349 & 0.133 & -0.064 & 0.313 \\
I & -0.067 & 0.362 & -0.006 & -0.005 & 0.361 \\
\hline
\end{tabular}

pack in a herringbone arrangement (Figure 3) in the crystalline regions [36].

These overall interactions can be well expressed in terms of interactions between local dipole moments of monomers. The local alignment of monomers' dipole moments in solution with respect to the orientation of the polymer chain determines the electrochemical properties of the polymer formed on electrode surface.

In addition, the orientation of monomer in the double layer of the solution in an electropolymerization cell depends on both size and direction of the dipole moment vectors of both monomers and polymer chain [35].

It is necessary to study the dipole moments of these chlorothiophenes to be able to predict their electropolymerization properties. The size of the dipole moment vector and its components calculated for chlorothiophenes in this study are presented in Table 4.

An analysis of calculated dipole moments shows that the orientation of the dipole moment vector is toward sulfur atom for all chlorothiophenes. The size and direction of the dipole moment vector is more dependent on the position (symmetry) of substituent than its number.

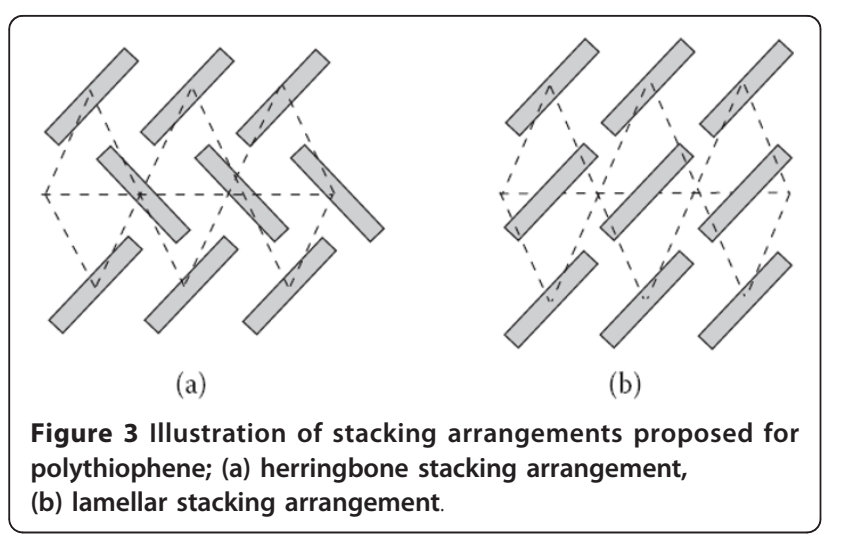

It can also be seen in Table 4 that the dipole moments for all compounds have the following trend:

$$
\mathrm{C}>\mathrm{F}>\mathrm{G}>\mathrm{A}>\mathrm{B}>\mathrm{E}>\mathrm{I}>\mathrm{H}>\mathrm{D}>\text { Thiophene }
$$

The size of the dipole moment vector for monomers $\mathbf{C}$ and $\mathbf{F}$ is greater than other compounds. Therefore, compounds $\mathbf{C}$ and $\mathbf{F}$ have a high solubility in polar solvents. These characteristics increase the efficiency of electrochemical polymerization processes of these monomers. Moreover it can be seen in Table 4 that thiophene has a low solubility in polar solvents.

\section{Ionization Potentials}

The first step in the electropolymerization of conducting polymers is formation of intermediate radical cations from monomers which can be considered as an ionization reaction [37].

$$
\mathrm{M} \rightarrow \mathrm{M}^{++}+\overline{\mathrm{e}}
$$

where $\mathrm{M}$ and $\mathrm{M}^{+}$denote monomer and its radical cation respectively. So, stability of intermediate radical cations has an important role in the electropolymerization process.

Therefore, it is useful to calculate electronic energy deference between the neutral monomer (as the initial species) and positively charged monomer (as the intermediate). This energy difference is proportional to Ionization Potential (IP) of the monomer. Calculated values of IP for chlorothiophenes based on Equation 2 are presented in Table 4. The trend of electrochemical stability of these monomers is:

$$
\text { F }>\text { B }>\text { Thiophene }>\mathrm{G}>\mathrm{D}>\mathrm{C}>\mathrm{A}>\mathrm{I}>\mathrm{H}>\mathrm{E}
$$

Since ionization potential energies are directly proportional to the electrochemical oxidation potentials of the compounds, it can be said that the electrochemical stability of monomers $\mathbf{F}$ and $\mathbf{B}$ are greater than other compounds.

\section{Electric Polarizabilities}

Values of Polarizabilities of compounds containing halogen are used to interpret light scattering and intensities of vibrational Raman spectra [34]. Values of exact electrical polarizabilities for all chlorothiophenes have been calculated and listed in Table 4. Based on this table, it can be claimed that with an increase in the number of chlorine atoms on the thiophene ring, polarization values will increase as well.

The zero values obtained for polarizabilities $\boldsymbol{\alpha}_{x z}$, and $\boldsymbol{\alpha}_{y z}$ are consequences of the planar structure. The small values of $\alpha_{x y}$ polarizabilities indicate that the delocalization strength of the $\pi$-system of the ring dominates the anisotropic effects of substituent for asymmetric chlorothiophenes. 
Table 4 Electric dipole moments, polarizability tensor elements, and ionization potentials calculated at B3LYP/6-311+ $+G^{* *}$ level of theory for the optimized structures of Thiophene and Chlorothiophenes

\begin{tabular}{ccccccccc}
\hline \multirow{2}{*}{ Molecule } & \multicolumn{3}{c}{ Electric dipole moment (D) } & \multicolumn{3}{c}{ Polarizabilities (Å) } & \multicolumn{3}{c}{ Ionization potentials (ev) } \\
\cline { 2 - 9 } & $\boldsymbol{\mu}_{\mathbf{x}}$ & $\boldsymbol{\mu}_{\mathbf{y}}$ & $\boldsymbol{\mu}_{\text {tot }}$ & $\boldsymbol{\alpha}_{\mathbf{x x}}$ & $\boldsymbol{\alpha}_{\mathbf{y y}}$ & $\boldsymbol{\alpha}_{\mathbf{z z}}$ & $\boldsymbol{\alpha}_{\mathbf{x y}}$ & IP \\
\hline Thiophene & 0.0000 & -0.5169 & 0.5169 & 67.093 & 73.851 & 41.017 & 0.012 & 8.75 \\
A & 1.2229 & -1.1156 & 1.6553 & 83.379 & 90.474 & 45.543 & -0.424 & 8.53 \\
B & 0.4885 & -1.3293 & 1.4162 & 73.843 & 99.340 & 45.713 & 0.914 & $\mathbf{8 . 7 7}$ \\
C & 2.0522 & -0.6022 & $\mathbf{2 . 1 3 8 8}$ & 105.378 & 99.760 & 50.761 & 1.770 & 8.56 \\
D & -0.0085 & -0.6768 & 0.6768 & 118.479 & 89.726 & 50.349 & 5.704 & 8.58 \\
E & -0.0014 & -1.1668 & 1.1668 & 124.387 & 85.513 & 50.238 & 0.006 & 8.38 \\
F & 1.9947 & -0.3062 & $\mathbf{2 . 0 1 8 1}$ & 113.075 & 91.086 & 50.781 & -3.497 & $\mathbf{9 . 0 0}$ \\
G & 0.2028 & -1.8053 & 1.8166 & 123.767 & 114.854 & 56.216 & 6.267 & 8.66 \\
H & -0.3414 & -0.6487 & 0.7331 & 117.232 & 125.636 & 55.339 & 14.351 & 8.44 \\
I & 0.7756 & -0.6432 & 1.0077 & 135.731 & 138.834 & 61.933 & 7.424 & 8.50 \\
\hline
\end{tabular}

$\mu_{z}, \alpha_{x z}$ and $\alpha_{y z}$ are essentially zero for all compounds because of the planar structure.

\section{Vibrational Spectra}

The vibrational frequencies for all chlorothiophenes were calculated using optimized structures at B3LYP/6$311++G^{* *}$ level of theory. Calculated IR absorption frequencies and intensities for all chlorothiophenes are presented in Table 5. To facilitate the comparison the frequencies are divided into low-frequency (below 1000 $\mathrm{cm}^{-1}$ ) and high-frequency groups (above $1000 \mathrm{~cm}^{-1}$ ). According to analysis of frequencies listed in Table 5, it can be suggested that thermal decomposition has the following trend:

Thiophene $>\mathrm{B}>\mathrm{A}>\mathrm{F}>\mathrm{D}>\mathrm{C}>\mathrm{E}>\mathrm{H}>\mathrm{G}>\mathrm{I}$
Thiophene and 3-chlorothiophene have the highest lowfrequency values among all these compounds; this means that thiophene and 3-chlorothiophene have the largest force constants for their bending modes of vibration. Higher values of low frequencies obtained for thiophene and 3-chlorothiophene can be regarded as higher protection from thermal decomposition for these molecules.

The calculated Zero-Point vibrational Energy (ZPE) for thiophene and all chlorothiophenes are listed in Table 6. Having in mind the contents of the table it can be said that ZPE for thiophene is greater than other compounds, as a result the relative thermal stability of thiophene is higher than other compounds.

Table 5 B3LYP/6-311++G** calculated IR absorption frequencies in $\mathrm{cm}^{-1}$ (intensities in $\mathrm{km} / \mathrm{mol}$ ) for Thiophene and Chlorothiophenes

\begin{tabular}{|c|c|c|}
\hline Molecule & Low - frequency range & High - frequency range \\
\hline Thiophene & $\begin{array}{l}460(0.67) 577(0.0) 619(0.37) 697(0.0) 727(143) 751(0.41) 842(26.9) \\
886(1.63) 894(0.30) 928(0.0)\end{array}$ & $\begin{array}{l}1017(3.15) 1069(4.45) 1070(0.0) 1234(11.37) 1348(0.71) 1397 \\
(11.2) 1501(0.24) 3093(3.85) 3107(3.7) 3139(0.04) 3142(1.20)\end{array}$ \\
\hline A & $\begin{array}{l}208(0.72) 264(0.13) 438(4.5) 471(4.17) 566(0.36) 655(5.28) 655(83.78) 854 \\
(20.46) 920(0.13) 969(50.73)\end{array}$ & $\begin{array}{l}1033(11.23) 1075(1.96) 1206(9.34) 1329(2.19) 1406(48.15) \\
1512(8.91) 3100(3.84) 3120(0.21) 3143(0.78)\end{array}$ \\
\hline B & $\begin{array}{l}210(0.51) 289(0.11) 426(4.34) 462(0.0) 611(15.8) 642(4.36) 682(3.5) 783 \\
(84.55) 812(1.54) 862(24.13) 886(0.01) 912(44.03)\end{array}$ & $\begin{array}{l}1061(7.04) 1184(15.57) 1184(8.76) 1342(24.13) 1395(1.59) \\
1499(29.97) 3119(0.42) 3145(0.39) 3155(3.64)\end{array}$ \\
\hline C & $\begin{array}{l}158(0.12) 175(0.04) 240(1.51) 317(1.12) 418(1.45) 476(1.16) 497(5.84) 608 \\
(14.78) 680(6.04) 717(47.74) 815(0.53) 892(64.40) 897(1.62) 991(40.60)\end{array}$ & $\begin{array}{l}1078(0.73) 1144(15.97) 1327(16.33) 1405(27.92) 1508(27.40) \\
3118(0.85) 3144(1.22)\end{array}$ \\
\hline D & $\begin{array}{l}159(0.05) 189(0.27) 247(0.01) 327(0.52) 393(1.20) 466(6.33) 471(1.12) 505 \\
(11.54) 687(9.9) 732(32.32) 833(35.74) 834(23.82) 883(42.25) 978(38.80)\end{array}$ & $\begin{array}{l}1066(12.21) 1158(10.25) 1313(31.22) 1409(33.17) 1506(70.38) \\
3132(1.66) 3154(6.58)\end{array}$ \\
\hline E & $\begin{array}{l}117(0.01) 194(0.10) 273(0.0) 318(0.73) 362(1.33) 486(14.08) 527(19.39) 552 \\
(0.0) 672(1.37) 728(3.32) 799(46.01) 884(0.0) 982(7.20) 985(140.11)\end{array}$ & $\begin{array}{l}1048(0.42) 1189(5.80) 1196(1) 1419(33.77) 1521(38.74) 3111 \\
(0.94) 3122(0.14)\end{array}$ \\
\hline F & $\begin{array}{l}170(0.0) 179(0.48) 242(1.90) 335(0.14) 454(4.75) 458(0.65) 467(1.14) 633(0.0) \\
692(20.02) 707(0.0) 800(67.63) 860(1.4) 863(24.2) 967(62.3)\end{array}$ & $\begin{array}{l}1104(19.3) 1142(0.1) 1318(58.4) 1491(7.9) 1491(13.2) 3154 \\
(6.8) 3155(3.10)\end{array}$ \\
\hline G & $\begin{array}{l}94(0.04) 179(0.02) 187(0.11) 237(1.3) 241(0.19) 363(1.3) 367(0.57) 456(3.83) \\
481(0.14) 541(3) 658(2.6) 732(33.4) 775(46.6) 856(3.9) 928(71.1)\end{array}$ & $\begin{array}{l}\text { 1009(3.9) 1120(16.22) 1297(79.65) 1410(17.9) 1498(37.1) } 3155 \\
(7.6)\end{array}$ \\
\hline$H$ & $\begin{array}{l}115(0.0) 178(0.0) 173(0.05) 187(0.0) 279(0.15) 355(1.5) 364(1.5) 420(1.8) 493 \\
(8.6) 582(21) 505(1.8) 695(3.1) 831(20.1) 853(61.7) 972(4.15) 999(85.6)\end{array}$ & $1123(14.1) 1289(20.6) 1421(13.9) 1516(86) 3130(4.67)$ \\
\hline । & $\begin{array}{l}88(0.0) 114(0.02) 177(0.0) 181(0.05) 191(0.09) 236(0.91) 271(0.0) 489(4.6) 363 \\
(0.14) 364(1.4) 403(2.6) 456(3.17) 514(2.15) 657(0.0) 671(22.11) 809(45.32) \\
896(61.9) 972(168)\end{array}$ & $1025(28) 1270(87)$ 1424(1.24) 1505(75) \\
\hline
\end{tabular}


Table 6 Zero-Point vibrational energy in $\mathrm{kcal} / \mathrm{mol}$, calculated at B3LYP/6-311++G** level of theory for the optimized structures of Thiophene and Chlorothiophenes

\begin{tabular}{cc}
\hline Molecule & ZPE \\
\hline Thiophene & $\mathbf{4 1 . 6 4}$ \\
A & 35.85 \\
B & 35.81 \\
C & 30.01 \\
D & 29.92 \\
E & 29.97 \\
F & 29.93 \\
G & 24.07 \\
H & 24.09 \\
I & 18.20 \\
\hline
\end{tabular}

\section{NMR Chemical Shifts}

The NMR chemical shifts can be used to predict ring current and estimate aromaticity of all chlorothiophenes [38-40]. ${ }^{13} \mathrm{C}$ chemical shielding have been calculated for DFT-B3LYP/6-311++G** optimized geometries of all chlorothiophenes. The isotropic and anisotropic magnetic shielding have been calculated using GIAO and CSGT methods [41-43].

Values of chemical shifts in Positions $C_{2}$ and $C_{3}$ for all chlorothiophenes are calculated and presented in Figure 4. It can be seen from this figure that compounds $\mathbf{B}$ and
F have the lowest chemical shifts in Position $C_{2}$, these molecules have the highest chemical shifts in Position $\mathrm{C}_{3}$, as well. It should be noted that these compounds had the highest values of spin-density in their Position $C_{3}$.

\section{NICS Analysis}

The Nuclear Independent Chemical Shift (NICS) at GIAO/B3LYP/6-311++ $\mathrm{G}^{* * *}$ and magnetic susceptibilities at CSGT/B3LYP/6-311++G**: level of theory [44-49] in center, 0.5 and 1 angstrom upper than thiophene ring have been calculated and listed in Table 7. Negative values of NICS represent the magnetic shielding and electric current in cyclic compounds. NICS results showed that compounds $\mathbf{B}$ and $\mathbf{F}$ have the highest NICS values in rings center, 0.5 and 1 angstrom upper than thiophene ring; these compounds have the largest electrical current and most conductivity among all other compounds. Based on this table, it can be claimed that the magnetic susceptibilities of these molecules increase with the number of the chlorine atoms, as well.

\section{Conclusion}

B3LYP method with $6-311++G^{* * *}$ basis set calculations have been carried out successfully to study the structural, electric and spectroscopic properties of all chlorothiophenes. Values of dipole moment, spin density distribution, ionization potential, vibrational frequencies

(a)

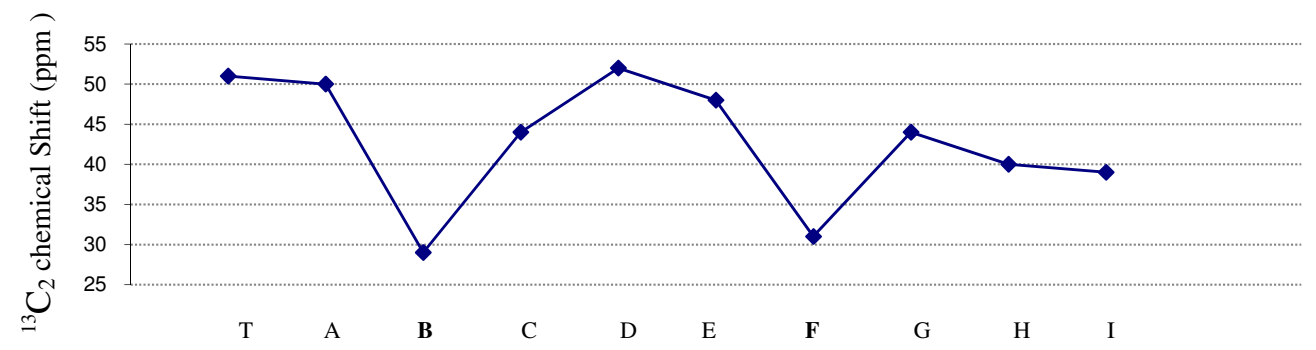

Chlorothiophenes

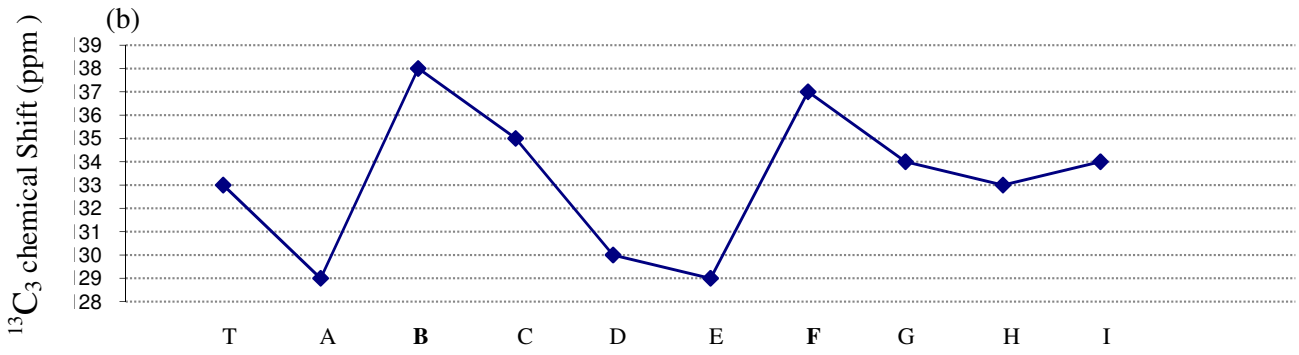

Chlorothiophenes

Figure 4 GIAO calculated values of the chemical shifts for Thiophene and chlorothiophenes (referenced to TMS); (a) ${ }^{13} \mathrm{C}_{2}$ chemical shifts, (b) ${ }^{13} C_{3}$ chemical shifts. 
Table 7 Calculated NICS values (ppm) at GIAO/B3LYP/6$311++G^{* *}$ and magnetic susceptibilities (cgs-ppm) at CSGT/B3LYP/6-311++G** for Thiophene and Chlorothiophenes

\begin{tabular}{ccccc}
\hline Molecule & NICS(0) & NICS(0.5) & NICS(1) & $\chi$ \\
\hline Thiophene & -11.91 & -11.49 & -9.28 & -51.86 \\
A & -12.30 & -11.54 & -9.05 & -68.66 \\
B & -13.49 & -12.22 & -9.57 & -69.26 \\
C & -12.57 & -11.45 & -8.67 & -86.79 \\
D & -12.77 & -11.50 & -8.56 & -85.45 \\
E & -12.13 & -10.91 & -8.19 & -85.24 \\
F & -13.51 & -12.12 & -9.31 & -86.81 \\
G & -13.48 & -11.87 & -8.60 & -104.38 \\
H & -12.48 & -10.90 & -7.81 & -103.01 \\
I & -13.31 & -11.38 & -7.93 & -123.23 \\
\hline
\end{tabular}

and NICS have been calculated and analyzed. The analysis of the data showed that 3-chlorothiophene has the smallest values of the $\boldsymbol{F}_{\boldsymbol{n}}$ coefficient. Therefore, it can be suggested that double bonds in 3-chlorothiophene are more delocalized. Electrochemical stability of 3-chlorothiophene and 3,4-dichlorothiophene is greater than other chlorothiophenes. Thermal stability and ZeroPoint Energy of thiophene are greater than all chlorothiophenes. The 3-chlorothiophene and 3, 4-dichlorothiophene possesses the largest NICS value; these compounds have the largest electrical current in the thiophene ring. Accordingly, compound B (3-chlorothiophene) is the best candidate monomer among all chlorothiophenes for the synthesis of corresponding conducting polymers with modified characteristics. The synthesis feasibility, experimental measurement and thermo chemical stability of these chlorothiophenes are interesting subjects for study.

\section{Acknowledgements \\ This research was supported by the Islamic Azad University, Toyserkan Branch, Toyserkan, Iran.}

\section{Author details}

${ }^{1}$ Young Researchers Club, Islamic Azad University, Toyserkan Branch, Toyserkan, Iran. ${ }^{2}$ Department of Chemistry, Islamic Azad University, Toyserkan Branch, Toyserkan, Iran.

\section{Authors' contributions \\ SJ-B proposed and supervised the program, and participated in data analysis and draft reversion, coordinated the study and modified the text. HS participated in data collection and manuscript drafting, completed the molecular design, the arrangement of the work and modification of the manuscript. SJ-B and HS participated in the separation and purification of compounds, acquisition of data, and collection of literature and helped to draft the manuscript. Authors read and approved the final manuscript.}

\section{Competing interests}

The authors declare that they have no competing interests.

Received: 17 September 2010 Accepted: 14 March 2011 Published: 14 March 2011
References

1. Jameh-Bozorghi S, Shirani ILH: Theoretical study on the electronic, structural, properties and reactivity of a series of mono-, di-, tri- and tetrafluorothiophenes as well as corresponding radical cation forms. J Fluor Chem 2011.

2. MacDiarmid AG: Synthetic metals: A novel role for organic polymers. Chem Int E 2001, 40:2581-2585.

3. Hall AW, Blackwood KM, Milne PE, Goodby JW: Novel UV cured coatings and adhesives based on the photoinitiated cyclopolymerization of derivatives of diallylamine. Chem Commun 2003, 2530-2531.

4. Neves S, Gazotti WA, De Paoli M-A: Conducting Polymeric Nanomaterials. In In Encyclopedia of Nanoscience and Nanotechnology. Volume 2. Edited by: Nalwa HS. Los Angeles: American Scientific Publishers; 2004:133-152.

5. Gangopadhyay R: Conducting Polymer Nanostructures. In In Encyclopedia of Nanoscience and Nanotechnology. Volume 2. Edited by: Nalwa HS. Los Angeles: American Scientific Publishers; 2004:105-131.

6. Wallace GG, Innis PC, Kane-Maguire LAP: Inherently Conducting Polymer Nanostructures. In In Encyclopedia of Nanoscience and Nanotechnology. Volume 4. Edited by: Nalwa HS. Los Angeles: American Scientific Publishers; 2004:113-130.

7. Epstein AJ: Introduction to Electronic Polymers: Influence of Nanostructure on Electronic Phenomena. In In Organic Electronic Materials: Conjugated Polymers and Low Molecular Weight Organic Solids. Volume 41. Edited by: Farchioni R, Grosso G. Amsterdam: Springer; 2001:3-39.

8. Kolla HS, Surwade SP, Zhang X, MacDiarmid AG, Manohar SK: Absolute molecular Weight of Polyaniline. J Am Chem Soc 2005, 127:16770-16771.

9. Richard SP, Rajasekhar M, Subramania A: Synthesis of polythiophene nanoparticles by surfactant - assisted dilut polymerization method for high performance redox supercapacitors. Int J Electrochem Sci 2009, 4:1289-1301.

10. Bai H, Shi G: Gas sensors based on conducting polymers. Sensors 2007, 7:267-307.

11. Henry D, Tran YW, Julio MD, Richard BK: Toward an understanding of the formation of conducting polymer nanofibers. ACS Nano 2008, 2:1841-1848.

12. Ohkawa S, Ohta R, Kawabata K, Goto H: Polymerization in liquid crystal medium: preparation of polythiophene derivatives bearing a bulky pyrimidine substituent. Polymers 2010, 2:393-406.

13. Viinikanoja A, Lukkari J, Aaritalo T, Laiho T, Kankare J: Phosphonic acid derivatized polythiophene: $A$ building block for metal phosphonate and polyelectrolyte multilayers. Langmuir 2003, 19:2768-2775.

14. Grevin B, Rannou P: Electrochemistry: Arrays of polymer nanowires. Nature Materials 2004, 3:503-504.

15. Nishinaga T, Yamazaki D, Tateno M, lyoda M, Komatsu K: Synthesis and properties of octithiophene dication sterically segregated by annelation with bicycle [2.2.2]octene units. Materials 2010, 3:2037-2052.

16. Lipton-Duffin JA, Miwa JA, Kondratenko M, Cicoira FB, Sumpter G, Meunier V, Perepichka DF, Rosei F: Step-by-step growth of epitaxially aligned polythiophene by surface-confined reaction. PNAS 2010, 107:11200-11204.

17. Ramanathan K, Bangar M, Yun M, Chen W, Myung N, Mulchandani A: Bioaffinity sensing using biologically functionalized conducting-polymer nanowire. J Am Chem Soc 2005, 127:496-497.

18. Wayne E, Jones Jr, Chiguma J, Johnson E, Pachamuthu A, Santos D: Electrically and thermally conducting nanocomposites for electronic applications. Materials 2010, 3:1478-1496.

19. Wan MX: Conducting Polymer Nanotubes. In In Encyclopedia of Nanoscience and Nanotechnology. Volume 2. Edited by: Nalwa HS. Los Angeles, American Scientific Publishers; 2004:153-169.

20. Maddalena F, Meijer EJ, Asadi K, Leeuw DM, Blom PWM: Doping kinetics of organic Semiconductors investigated by field-effect transistors. Appl Phys Lett 2010, 97:0433021-0433023.

21. Yang L, Qi Y, Yuan X, Shen J, Kim J: Direct synthesis, characterization and catalytic application of SBA-15 containing heteropolyacid. Journal of Molecular Catalysis A: Chemical 2005, 229:199-205.

22. Wallace GG, Spinks GM, Kane-Maguire LAP, Teasdale PR: Synthesis and Properties of Polythiophenes. In Conductive electroactive polymers: intelligent polymer systems Queensland: CRC Press; 2009, 197-226.

23. Lukkari J, Viinikanoja A, Paukkunen J, Salomaki M, Mervi Janhonen, Aaritalo T, Kankare J: Oxidation induced variation in polyelectrolyte multilayers prepared from sulfonated self-dopable poly (alkoxythiophene). Chem Commun 2000, 571-572. 
24. Asami R, Fuchigami T, Atobe M: Development of a novel environmentally friendly electropolymerization of water-insoluble monomers in aqueous electrolytes using acoustic emulsification. Langmuir 2006, 22:0258-10263.

25. Chen J, David LO, Jennifer MP, Douglas RMF, Chee OT, Gordon GW: Photoelectrochemical solar cells based on polyterthiophenes containing porphyrins using ionic liquid electrolyte. Electrochemical and Solid-State Letters 2005, 8:A528-A530.

26. Silvestri F, Marrocchi A: Acetylene-Based materials in organic photovoltaics. Int J Mol Sci 2010, 11:1471-1508.

27. Oterom TF, Azelain EL: Synthesis and properties of polythiophenes. Polym Comm 1988, 29:21-50.

28. Alvaro AA, Rosa LT: Study of kinetic formation and the electrochemical behavior of polypyrrole films. J Chil Chem Soc 2009, 54:14-19.

29. Wallace GG, Spinks GM, Kane-Maguire LAP, Teasdale PR: In Conductive electroactive polymers: intelligent polymer systems Queensland: CRC Press; 2009, 77-107.

30. Frisch MJ, Trucks GW, Schlegel HB, Scuseria GE, Robb MA, Cheeseman JR, Zakrazewski VG, Montgomery JA, Startmann RE, Burant JC, Dapprich S, Millam JM, Daniels AD, Kudin KN, Strain MC, Farkas O, Tomasi J, Barone V, Cossi M, Cammi R, Mennucci B, Adamo C, Clifford S, Ochterski J, Petersson GA, Ayala PY, Morokuma QCK, Malik DK, Rabuck AD, Raghavachar K, et al: GAUSSIAN 98 (Revision A3), Gaussian Inc Pittsburgh: PA; 1998.

31. Gross EK, Dreiz RM: Density Functional Theory New York: Plenum Press; 1995.

32. Carlier P, Deora N, Lam P, Harmon J, Williams L: Carlier group gaussian user manual 2010 [http://www.gaussian.com], Version 1.22.

33. Andersson MP, Uvdal P: New scale factors for harmonic vibrational frequencies using the B3LYP density functional method with the tripleBasis Set 6-311+G(d,p). J Phys Chem A 2005, 109:2937-2941.

34. Omrani A, Sabzyan H: Theoretical study of chloropyrroles as monomers for new conductive Polymers. J Phys Chem A 2005, 109:8874-8879.

35. Sabzyan H, Omrani A: Ab initio and DFT study of all Mono-, Di-, Tri- and Tetrafluoropyrroles and their cations: predicting structural, spectroscopic, electropolymerization and electrochemical properties. J Phys Chem A 2003, 107:6476-6482.

36. Wallace GG, Spinks GM, Kane-Maguire LAP, Teasdale PR: Processing and Device Fabrication. In Conductive electroactive polymers: intelligent polymer systems Queensland: CRC Press; 2009, 231-245.

37. Nikoofard H, Sabzyan H: DFT study of molecular structure and electronic properties of fluoromethylpyrrole oligomers including di-, tri- and tetramer. Journal of Fluorine Chemistry 2007, 128:668-673.

38. Kleinpeter $E$, Klod S: Ab initio calculation of the anisotropy effect of multiple bonds and the ring current effect of arenes-application in conformational and configurational analysis. J Chem Soc Perkin Trans 2001, 2:1893-1898.

39. Martin NH, Caldwell BC, Carlson KP, Teague MR: Ab initio calculation of through-space magnetic shielding of linear polycyclic aromatic hydrocarbons (acenes): Extent of aromaticity. J Mol Graph Model 2009, 27:689-692.

40. Chen Z, Wannere CS, Corminboeuf C, Puchta R, Schleyer PVR: NucleusIndependent Chemical Shifts (NICS) as an Aromaticity Criterion. Chem Rev 2005, 105:3842-3888.

41. Baldridge KK, Siegel JS: Correlation of empirical (TMS) and absolute NMR chemical shifts predicted by ab initio computations. J Phys Chem A 1999, 103:4038-4042.

42. Zhang Y, Wu A, Xu Xin, Yan Y: Geometric dependence of the B3LYPPredicted magnetic shielding and chemical shifts. J Phys Chem A 2007, 111:9431-9437.

43. Gaussian 03 Online Manual. [http://www.nd.edu/ wschnei1/courses/ CBE_547/g03_man/g_ur/k_nmr.htm].

44. Sabzyan $H$, Omrani $A$ : $A b$ initio and density functional study of electrical and thermochemical properties of mono-, di-, tri- and tetrafluoropyrroles and their cations and anions. J THEOCHEM 2005, 713:43-49

45. Schleyer PVR, Manoharan M, Wang Z-X, Kiran B, Jiao H, Puchta R, Hommes NJRVE: Dissected Nucleus-Independent Chemical Shift analysis of $\pi$-aromaticity and antiaromaticity. Org Lett 2001, 3:2465-2468.

46. Corminboeuf C, Heine T, Seifert G, Schleyer PVR, Weber J: Induced magnetic fields in aromatic [n]-annulenẽsinterpretation of NICS tensor components. Phys Chem Chem Phys 2004, 6:273-276.
47. Alkorta I, Rozas I, Elguero J: An ab initio study of the NMR properties (absolute shielding and NICS) of a series of significant aromatic and antiaromatic compounds. Tetrahedron 2001, 57:6043-6049.

48. Stanger A: Nucleus-Independent Chemical Shifts (NICS): Distance Dependence and Revised Criteria for Aromaticity and Antiaromaticity. $J$ Org Chem 2006, 71:883-893.

49. Fallah-Bagher-Shaidaei H, Wannere CS, Corminboeuf C, Puchta R, Schleyer PVR: Which NICS aromaticity index for planar m-rings is best? Org Lett 2006, 8:863-866.

doi:10.1186/1752-153X-5-13

Cite this article as: Shirani IL Beigi and Jameh-Bozorghi: Theoretical study on the electronic, structural, properties and reactivity of a series of mono-, di-, tri- and tetrachlorothiophenes as well as corresponding radical cation forms as monomers for conducting polymers. Chemistry Central Journal 2011 5:13.

Publish with ChemistryCentral and every
scientist can read your work free of charge
"Open access provides opportunities to our
colleagues in other parts of the globe, by allowing
anyone to view the content free of charge."
W. Jeffery Hurst, The Hershey Company.
- available free of charge to the entire scientific community
- peer reviewed and published immediately upon acceptance
- cited in PubMed and archived on PubMed Central
- yours - you keep the copyright
submit your manuscript here:
http://www.chemistrycentral.com/manuscript/

